\title{
Precancerous conditions and epithelial dysplasia in the stomach
}

\author{
BC MORSON, LH SOBIN, E GRUNDMANN, A JOHANSEN, T NAGAYO, AND \\ A SERCK-HANSSEN
}

From St Mark's Hospital, City Road, London ECIV 2PS, UK

SUMMARY A distinction can be made between a precancerous condition and a precancerous lesion. The former is a clinical state associated with a significantly increased risk of cancer, whereas a precancerous lesion is a histopathological abnormality in which cancer is more likely to occur than in its apparently normal counterpart. Up to the present time atrophic gastritis, gastric ulcer, pernicious anaemia, gastric stumps, gastric polyps, and Ménétrier's disease have all been considered as precancerous conditions and lesions of the stomach. Of these, only atrophic gastritis, pernicious anaemia, gastric stumps, and certain types of gastric polyp can now be regarded as having any really significant malignant potential. The precancerous lesion common to these is epithelial dysplasia which can occur in ordinary (foveolar) gastric epithelium as well as in intestinal metaplasia. The criteria for grading dysplasia in gastric epithelium into mild, moderate, and severe grades are given, and attention is drawn to the problems of differentiating inflammatory or regenerative change from mild dysplasia and intramucosal carcinoma from severe dysplasia. The clinical and epidemiological implications of gastric dysplasia are discussed with suggestions for further research.

When considering problems of premalignancy, it is essential to define exactly what is meant by this term. ${ }^{1}$ A distinction can be made between a precancerous condition and a precancerous lesion. ${ }^{2}$ The former is best regarded as a clinical state associated with a significantly increased risk of cancer, whereas a precancerous lesion is a histopathological abnormality in which cancer is more likely to occur than in its apparently normal counterpart. In many clinical conditions with an increased risk of cancer, there is also an identifiable precancerous lesion, but this is not invariably so.

The aim of this paper is to formulate histopathological criteria by which gastric lesions thought to have an increased risk of becoming carcinoma could be defined and classified with special reference to the incidence of epithelial dysplasia. This is essential for epidemiological, pathological, and clinical studies. The ultimate aim of such studies is to reduce the incidence and mortality of gastric cancer.

It is recognised that the word 'precancerous' does not imply the inevitability of developing a malignant lesion. It is rather a marker of an increased probability or risk of malignant change. The degree of this risk varies and in most cases the magnitude is

Received for publication 17 October 1979 not known. This is an important field for further research. Appropriate public health measures depend upon identifying individuals or populations at increased risk and estimating the magnitude of that risk.

Up to the present time the following conditions have been considered as precancerous on the basis of clinical, histological, and epidemiological evidence.

Precancerous conditions and lesions of the stomach

ATROPHIC GASTRITIS

This is a histological diagnosis. The main features are a variable degree of inflammation, atrophy of gastric glands, and often associated intestinal metaplasia, which changes are more commonly found in the antrum than in the body or the fundus of the stomach. ${ }^{3}$

Patients with atrophic gastritis are statistically at increased risk from cancer of the stomach ${ }^{4}$ but precise measurement of this risk is yet to be determined. There is a significant geographical relationship between areas of high frequency for gastric carcinoma and the incidence of atrophic gastritis and intestinal metaplasia. ${ }^{6-8}$ Within the histological spectrum of atrophic gastritis intestinal metaplasia is the most sensitive risk indicator, but in areas of 
high gastric cancer incidence (eg, Japan, Colombia, and Finland) it is still too prevalent to serve as a selective marker, especially in the older age groups.

Most gastric cancers develop on a basis of atrophic gastritis, but the epithelial change which statistically most predisposes to malignancy is intestinal metaplasia. ${ }^{9-11}$ However, we have observed dysplasia in ordinary (foveolar) gastric epithelium as well as in intestinal metaplasia. The degree of dysplasia in either type of epithelium could be a more accurate method of expressing the magnitude of increased cancer risk.

\section{GASTRIC ULCER}

The incidence of so-called 'ulcer-cancer', that is, carcinoma developing in a pre-existing peptic ulcer, has been debated hotly for many years. There are two essential criteria for the diagnosis: first, there must be definite evidence of a pre-existing ulcer (complete destruction of a zone of muscle, dense fibrous tissue in the floor of the lesion, endarteritis and thrombophlebitis in surrounding vessels, fusion of muscle coats and muscularis mucosae at the edge of the lesion), and, second, there must be definite evidence of malignant change at the edge of the ulcer quite distinct from any attempt at epithelial regeneration..$^{12}$ No studies have been reported on the significance of epithelial dysplasia at the margins of chronic gastric ulcers as an indicator of increased cancer risk. In any assessment one must remember that chronic ulcer and cancer may coexist in a stomach without necessarily being causally related; studies in Japan suggest that gastric ulcer and gastric cancer also have a different geographic distribution. ${ }^{13}$ Ulcer-cancers undoubtedly do occur, particularly when the ulcer is chronic, but the incidence of cancer developing in a proven peptic ulcer and the presence of unequivocal evidence of previous peptic ulcer at the site of a proven carcinoma are both probably not more than $1 \%{ }^{1415}$

PERNICIOUS ANAEMIA

There is statistical and histological evidence that patients with pernicious anaemia are at increased risk from cancer of the stomach. True adenomatous polyps and carcinoma of the stomach have been reported to be three to four times more common in patients with pernicious anaemia than in the general population, ${ }^{16} 17$ although a recent study suggests that this may be an underestimate, since some patients with carcinoma but without overt pernicious anaemia are in a 'pre-pernicious anaemia stage'.18 Moreover, it appears that the carcinomas are mostly found in the body or the fundus of the stomach rather than in the pyloric antrum, ${ }^{19} 20$ which is where most gastric cancers are seen. The histological features of the mucosa in pernicious anaemia are those of gastric atrophy with intestinal metaplasia of varying extent which may spare the antrum. ${ }^{21}$

Although pernicious anaemia patients are prone to develop gastric polypoid lesions, the lack of uniform definitions and terminology has resulted in conflicting information on the nature and relevance of such polyps. One report suggests that these polyps are invariably of the regenerative type. ${ }^{22}$

No studies have been reported on the role of dysplasia as a marker for increased cancer risk in pernicious anaemia. ${ }^{23}$

GASTRIC STUMPS

Patients who have had a partial gastrectomy for benign peptic ulcer are at increased risk for carcinoma in the gastric stump many years after the operation. ${ }^{24-27}$ There is evidence that such patients form a clinical risk group and should be monitored in order to detect precancerous changes ${ }^{28}$ but further research is required. Gastric stump carcinomas usually develop close to the anastomosis on the gastric side. Polypoid lesions are common in the same area, but their significance has not yet been established; many are hyperplastic or regenerative polyps, and others may be pseudopolyps resulting from the construction of the anastomosis.

\section{GASTRIC POLYPS}

Polypoid lesions of the stomach can be divided into those with and without malignant potential. The common ones, hyperplastic or regenerative polyps, have insignificant malignant potential. ${ }^{29-31}$ Polypoid lesions in which the epithelium shows dysplasia (which are called adenomas or borderline lesions by some $)^{32}$ have a significant capacity for malignant change.

In our opinion, adenomas can adopt a villous or tubulovillous (villoglandular) growth pattern and only rarely take the form of an adenomatous polyp (tubular adenoma) as seen in the colon. The majority of adenomatous polyps described in the literature were hyperplastic or regenerative polyps and not genuine adenomas. It is exceptional for gastric adenomas to have a stalk, particularly a long one, and most of them are sessile. They can be very flat, slightly elevated tumours and are more often single than multiple. Most gastric adenomas are of the intestinal type, which suggests that they have developed on a basis of atrophic gastritis and intestinal metaplasia, although we have seen severe cellular atypia in epithelium which in all other respects has the cytological and histochemical qualities of superficial (foveolar) epithelium.

Gastric adenomas are uncommon but have a very significant potential for malignant change. On the 


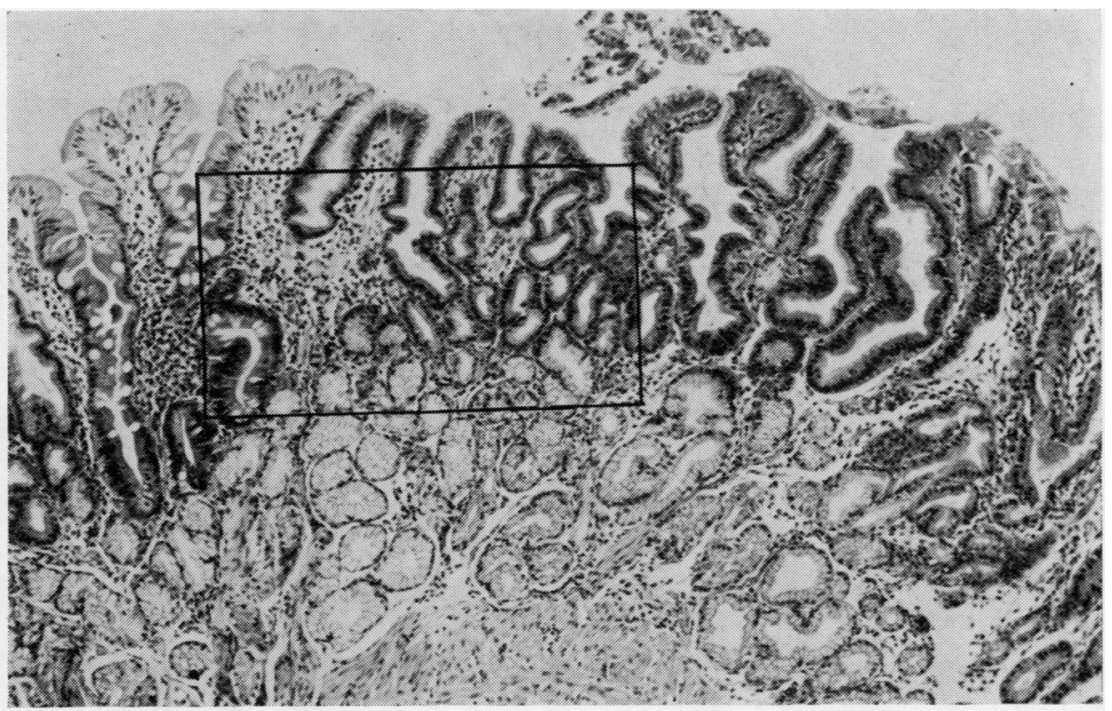

(a)

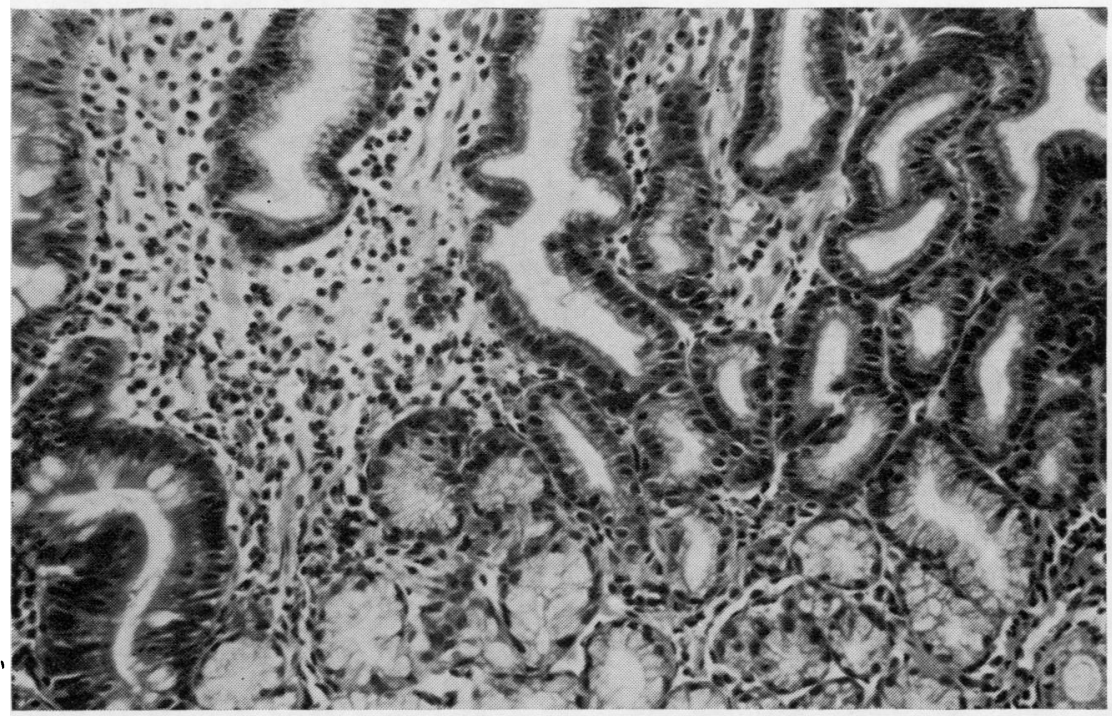

(b)

Fig. 1 Inflammatory or regenerative epithelial change in ordinary (foveolar) gastric epithelium. (a) Haematoxylin and eosin $\times 40$; (b) $H$ and $E \times 80$. 


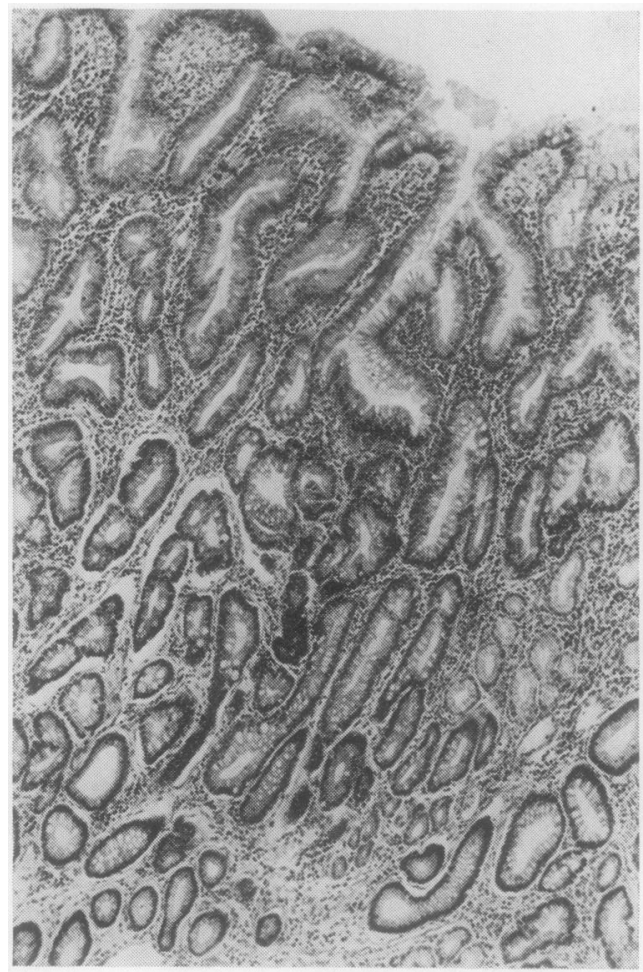

(a)

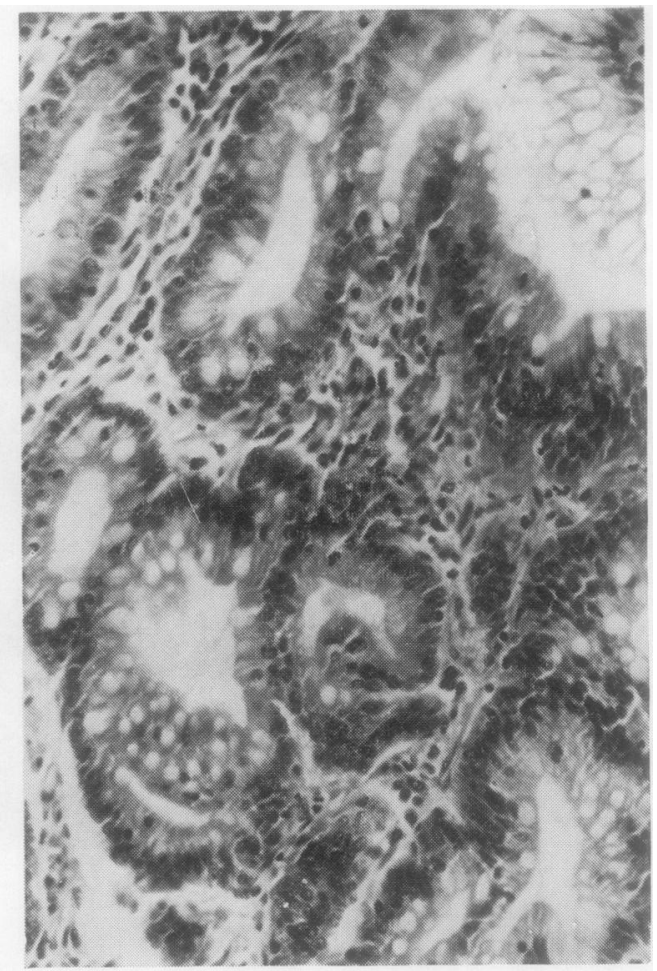

(b)

Fig. 2 Inflammatory or regenerative epithelial change in intestinal metaplasia. Original magnifications (a) $H$ and $E \times 80 ;(b) H$ and $E \times 210$.

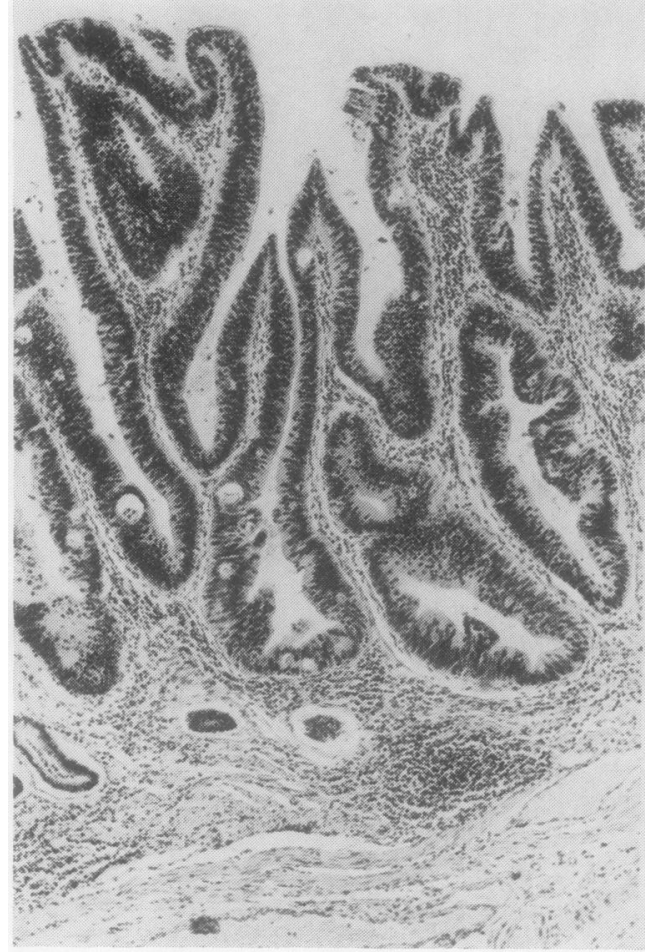

(a)



(b)

Fig. 3 (a) Severe epithelial dysplasia in ordinary gastric (foveolar) epithelium. Original magnification $H$ and $E$ $\times 60$. (b) Severe epithelial dysplasia in ordinary gastric (foveolar) epithelium. High-power view of (a). Original magnification $H$ and $E \times 250$. 


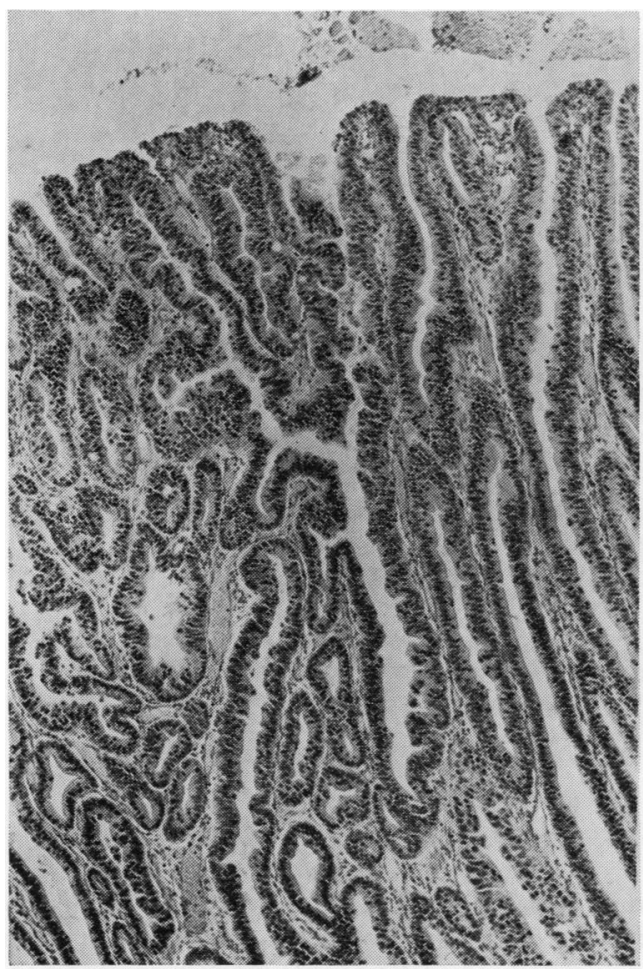

(a)

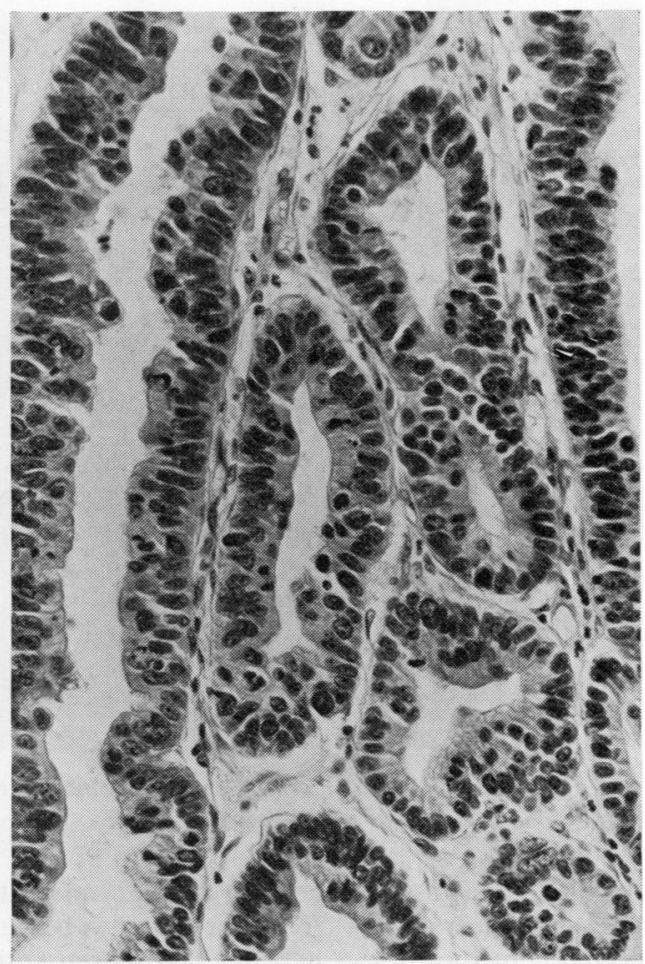

(b)

Fig. 4 (a) Severe epithelial dysplasia in intestinal metaplasia. Origit.al magnification $H$ and $E \times 60$. (b) Severe epithelial dysplasia in intestinal metaplasia. High-power view of (a). Original magnification $H$ and $E \times 250$.

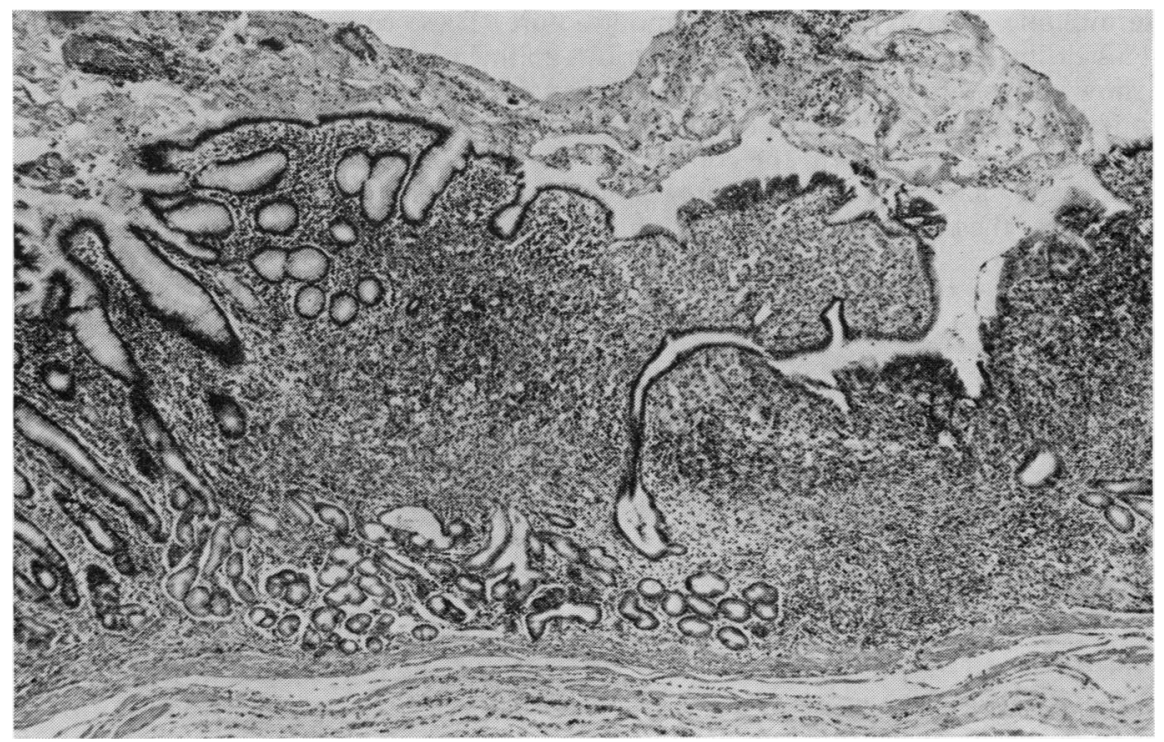

Fig. 5 Intramucosal carcinoma of stomach. The lamina propria is largely replaced by undifferentiated and signet ring carcinoma cells. $H$ and $E \times 10$. 




Fig. 6 Intramucosal adenocarcinoma of stomach. The distinction from severe epithelial dysplasia can be difficult. $H$ and $E \times 20$.

other hand, it is possible that only a small minority of gastric cancers arise from previously benign adenomas, but the subject is bedevilled by semantic issues. For example, the 'border-line lesion' 33 would be called a sessile tubular adenoma by many pathologists. On the other hand, it has been recognised that the diagnosis of benign adenoma must be made with care, because multiple sections through the tumour may show signs of intramucosal carcinoma. Gastric adenomas show varying degrees of epithelial dysplasia, sometimes amounting to carcinoma-insitu, but the use of this expression in the context of adenomas and early gastric cancer is probably undesirable in view of the difficulty of being sure that intramucosal invasion has not occurred. ${ }^{3}$

\section{MÉNÉTRIER'S DISEASE}

There is a growing list of case reports of carcinoma of the stomach complicating Ménétrier's disease. ${ }^{34-45}$ The statistical risk of cancer in this disease is not known, and anyway the diagnosis of Ménétrier's disease is difficult to define both clinically and pathologically. There are descriptions of both intestinal metaplasia and epithelial dysplasia of gastric epithelium in some of the reports.

\section{Epithelial dysplasia}

Attention has so far been concentrated on the above precancerous conditions and much less emphasis has been placed on epithelial dysplasia in the stomach as a marker for increased cancer risk. ${ }^{46-49}$ It is important that dysplasia should be defined and its significance evaluated as a possible marker common to all the above precancerous conditions.

The main histological and cytological features of epithelial dysplasia are cellular atypia, abnormal differentiation, and disorganised mucosal architecture. These can occur in ordinary gastric (foveolar) epithelium as well as in intestinal metaplasia, both of which may be the source of carcinoma.

\section{CELLULAR ATYPIA}

This is characterised by nuclear pleomorphism, hyperchromasia, nuclear stratification, increased nuclear-cytoplasmic ratio, sometimes increased cytoplasmic basophilia, and loss of cellular and nuclear polarity.

\section{ABNORMAL DIFFERENTIATION}

This is manifested by lack of, or reduced numbers of, goblet cells and Paneth cells in the metaplastic intestinal epithelium, or by a reduction, alteration, or disappearance of secretory products from the gastric epithelium.

DISORGANISED MUCOSAL ARCHITECTURE This has the following features: irregularity of crypt structure, back-to-back gland formation, budding and branching of crypts, and intraluminal and surface papillary growths.

The degree of epithelial alteration is a spectrum 


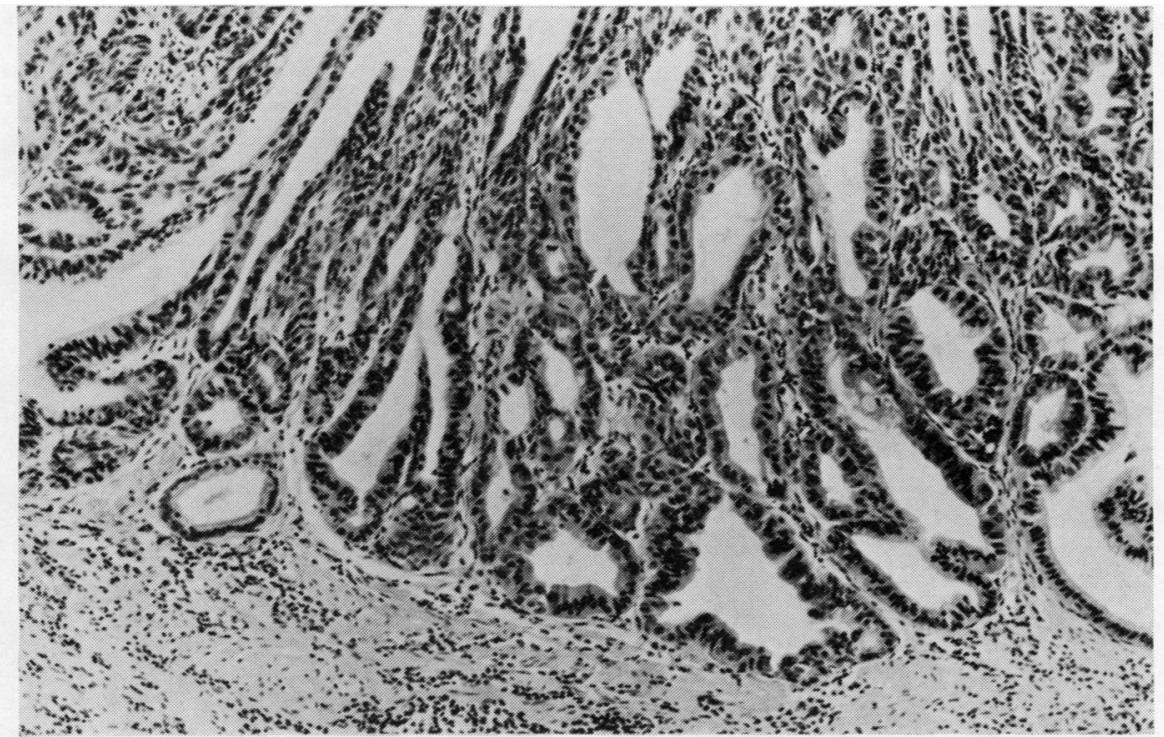

(a)

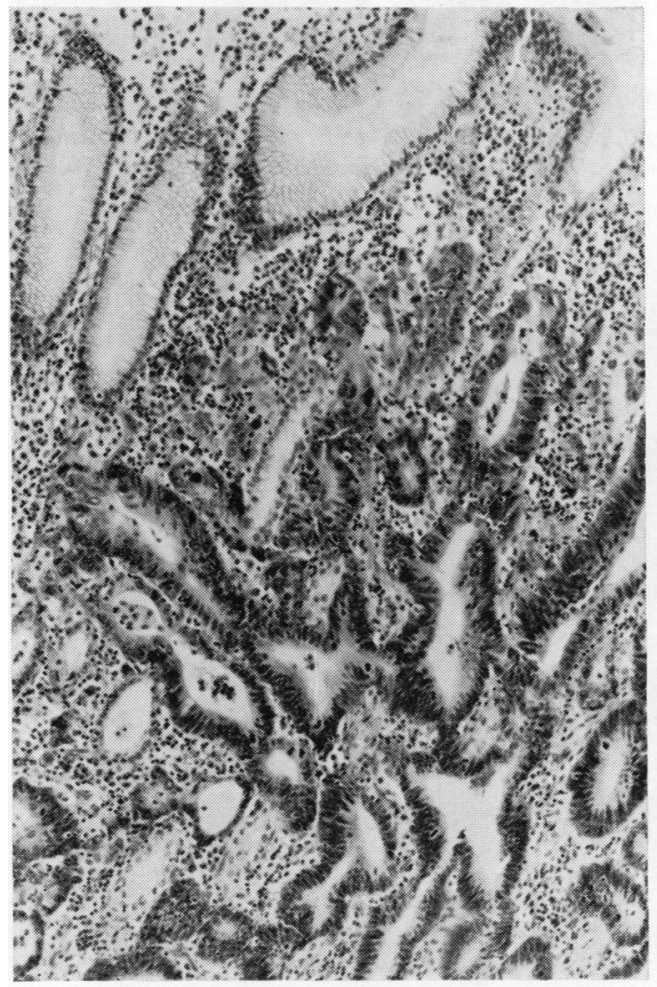

Fig. 7 (a) Intramucosal carcinoma of stomach; there is probable invasion of the lamina propria. High-power view. $H$ and $E \times 40$. (b) Intramucosal adenocarcinoma of stomach. The lamina propria shows invasion. High-power view. Original magnification $H$ and $E \times 60$.

(b) 


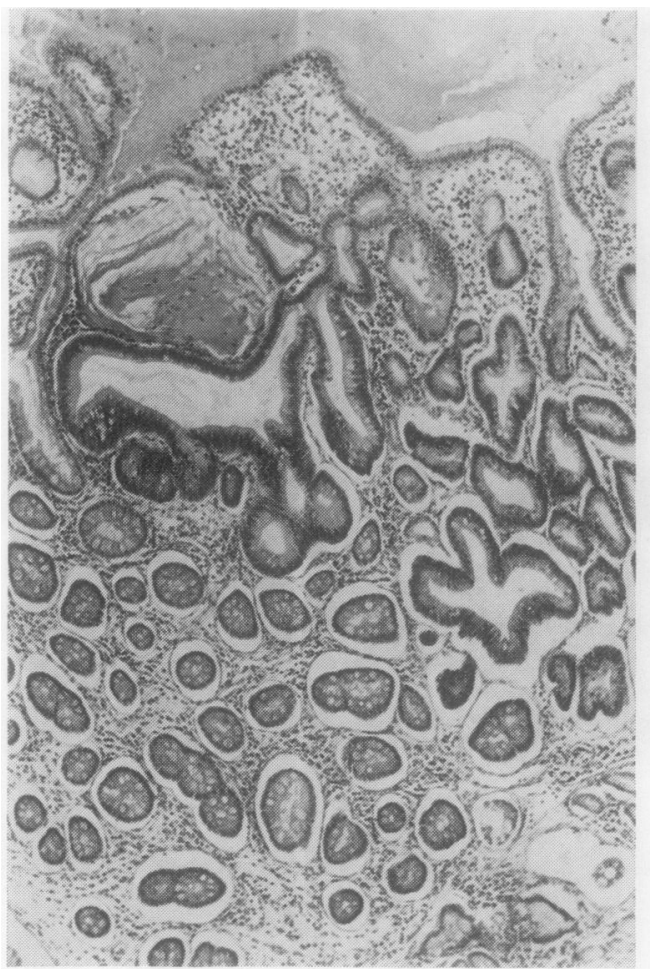

(a)

Fig. 8 (a) Mild epithelial dysplasia in intestinal metaplasia. Original magnification $H$ and $E \times 40$. (b) Mild epithelial dysplasia in intestinal metaplasia. High-power view of (a). Original magnification $H$ and $E \times 250$.

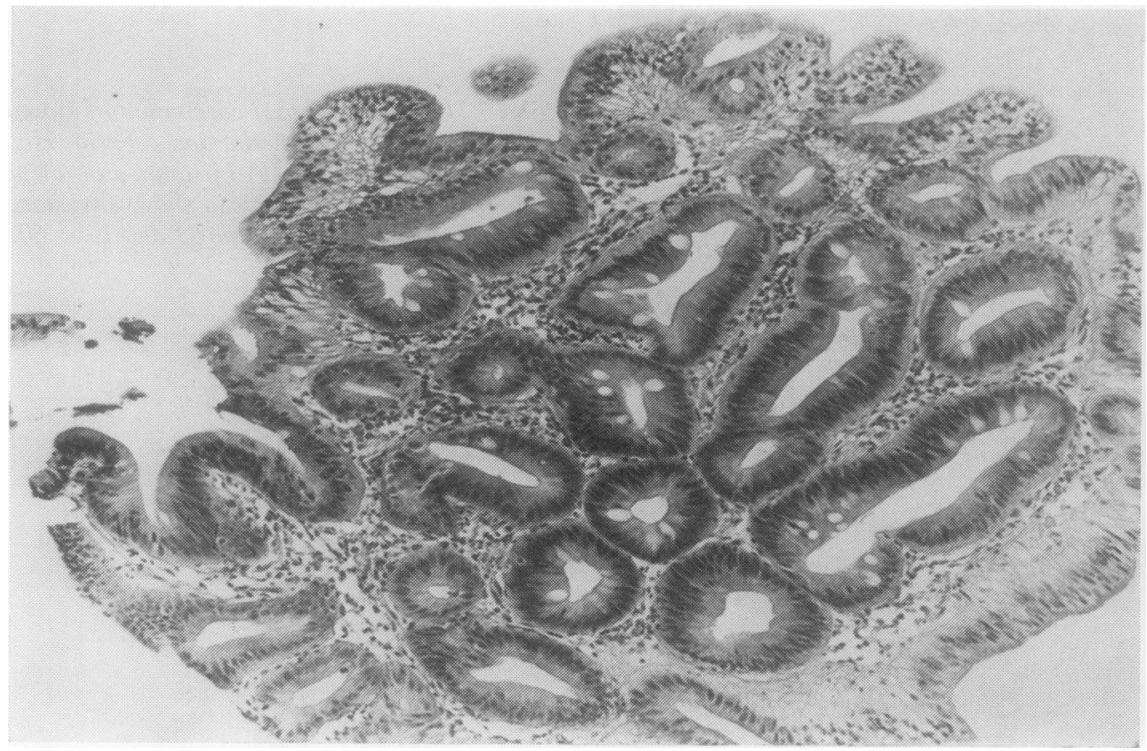

Fig. 9 Mild epithelial dysplasia in intestinal metaplasia. $H$ and $E \times 200$. 


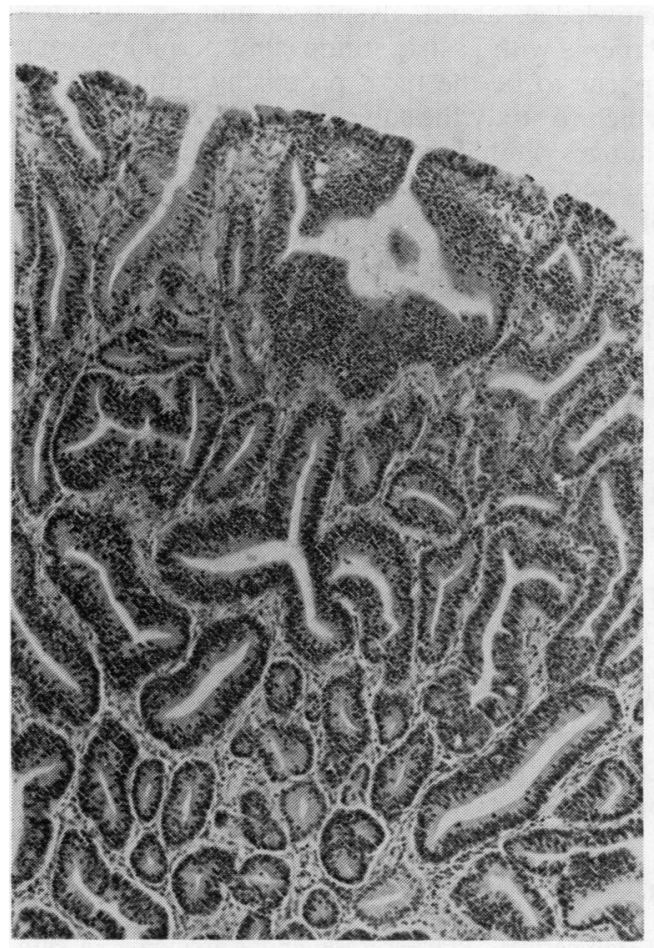

(a)

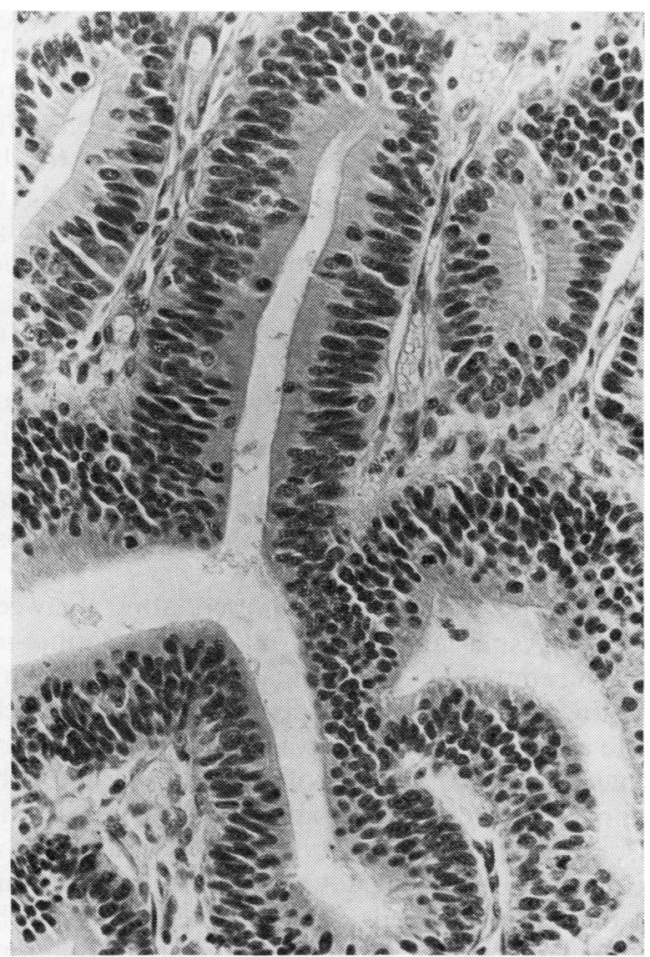

(b)

Fig. 10 (a) Moderate epithelial dysplasia in ordinary gastric (foveolar) epithelium. Original magnification $H$ and $E \times 60$. (b) Moderate epithelial dysplasia in ordinary gastric (foveolar) epithelium. High-power view of (a). Original magnification $H$ and $E \times 250$.

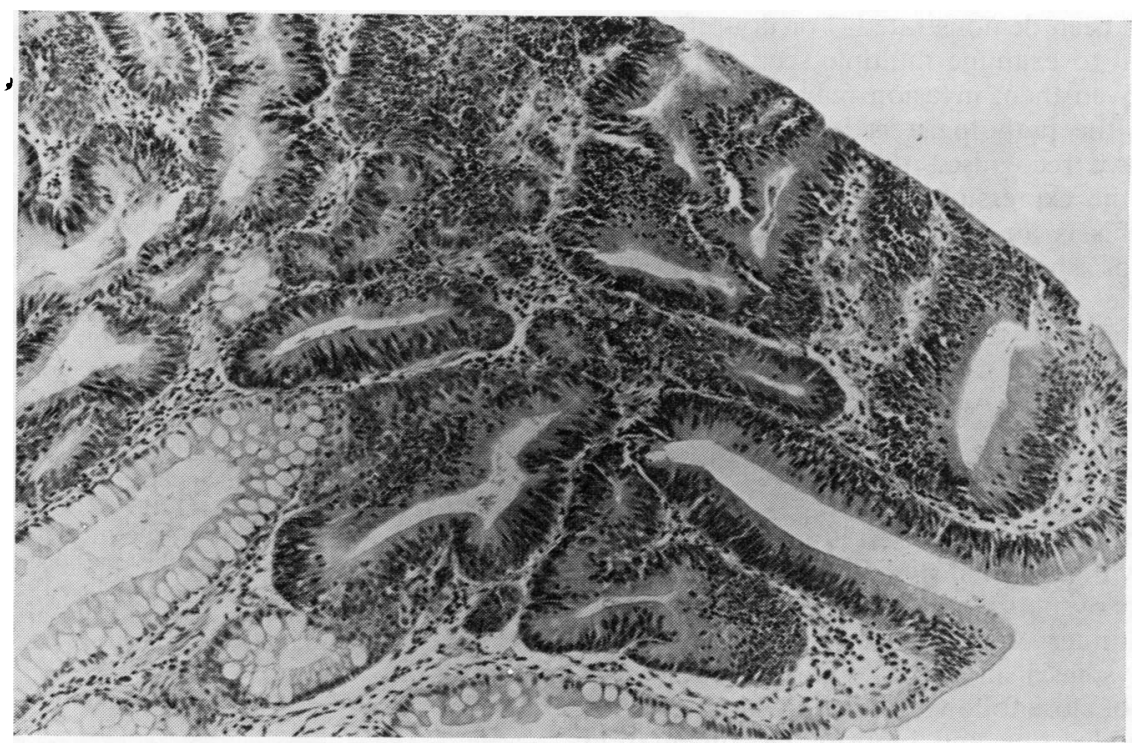

Fig. 11 Moderate epithelial dysplasia in intestinal metaplasia. High-power view. $H$ and $E \times 200$. 
of histological and cytological abnormalities which vary from those slight changes which are believed to be the result of inflammation and regeneration and are best termed inflammatory or regenerative epithelial change (Figs 1a, b and 2a, b), to the appearances of severe dysplasia (Figs $3 \mathrm{a}, \mathrm{b}$ and $4 \mathrm{a}, \mathrm{b}$ ) which stops short of intramucosal carcinoma (Figs $5,6,7 a, b)$. Less marked degrees are called mild (Figs $8 \mathrm{a}, \mathrm{b}$ and 9) and moderate (Figs 10a, b and 11) dysplasia. In lesions showing varying degrees of dysplasia, the most severe grade should be recorded. This scheme corresponds closely with that described by $\mathrm{Nagayo}^{33}$ and has some resemblance to the Japanese grouping system,,$^{50}$ except that the latter is used solely for biopsy diagnosis. The extent of dysplasia over the surface of the gastric mucosa might also be important.

There are problems of differentiating between epithelial dysplasia in gastric mucosa, carcinoma-insitu, intramucosal carcinoma, and what many pathologists would call an adenoma of the stomach. Severe epithelial dysplasia is used for the description of changes which fall short of the full criteria for the diagnosis of carcinoma-in-situ. The latter must exist at some stage in the progression into invasive carcinoma, but it is usually impossible to be certain that the neoplastic cells have not passed across the basement membrane of the crypts into the lamina propria without serial sectioning of the entire lesion, which is impracticable. For these reasons it is recommended that the expression carcinoma-in-situ be dropped in favour of intramucosal carcinoma, provided this is used only when lamina propria invasion has been demonstrated. For doubtful cases it is essential to examine multiple sections through the tissue. Even then, invasion may not be demonstrated and the pathologist is in a dilemma. The Japanese have recognised this problem and have introduced the expression 'border-line lesion'. For the purist this is an unsuitable expression for the description of a histological appearance, but it does illustrate the problem. Study of the Japanese literature suggests that what the Japanese are describing might be called an adenoma by many European and North American pathologists.

\section{Clinical implications and further research}

It is important to realise that the degree of risk associated with epithelial dysplasia is not yet established. Severe dysplasia on its own is not an indication for surgical intervention. However, experience of epithelial dysplasia in other organs suggests the importance of close follow-up for individual patients (including endoscopy and biopsy). Documentation must be adequate to provide an increasing body of knowledge about dysplasia and its significance. Patients with gastric stumps and pernicious anaemia appear to be the most promising clinical groups in which to study the subject further. Histopathological changes should be correlated with other potential markers of precancer, including cytology, contents of gastric juice, ${ }^{49}$ etc.

Up to the present time atrophic gastritis and intestinal metaplasia have been investigated as epidemiological markers for gastric cancer, but it appears even more informative to investigate the importance of gastric dysplasia in high and low risk areas for cancer of the stomach. It is hoped that information obtained by the evaluation of gastric dysplasia might be useful in the design of cancer prevention and detection programmes.

This work was supported by the World Health Organization and by the International Union against Cancer under the International Cancer Research Workshop Programme (ICREW).

We are grateful for advice from Dr PB Cotton, Dr AG Cox, and Dr MJ Hill, who attended the original meeting.

\section{References}

${ }^{1}$ Hamperl H. Präcancerose und Carcinoma in Situ. In: Grundmann E, ed. Geschwülste. Tumors. I (Handbuch der allgemeinen Pathologie, Vol. VI/5). Berlin and New York: Springer, 1974:351.

${ }^{2}$ World Health Organisation. Report of a WHO meeting on the Histological Definition of Precancerous Lesions. Geneva: WHO, 1972.

${ }^{3}$ Morson BC, Dawson IMP. Gastrointestinal Pathology, 2nd ed. Oxford: Blackwell Scientific Publications, 1979.

${ }^{4}$ Siurala M, Varis K, Wiljasalo M. Studies of patients with atrophic gastritis: a 10-15-year follow-up. Scand $J$ Gastroenterol 1966;1:40-8.

${ }^{5}$ Correa P, Cuello C, Duque E, et al. Gastric cancer in Colombia. III. Natural history of precursor lesions. J Natl Cancer Inst 1976;57:1027-35.

6 Bonne C, Hartz PH, Klerks JV, Posthuma JH, Radsma W, Tjokronegoro S. Morphology of the stomach and gastric secretion in Malays and Chinese and the different incidence of gastric ulcer and cancer in these races. $\mathrm{Am} \mathrm{J}$ Cancer 1938;33:265-79.

' Correa P, Cuello C, Duque E. Carcinoma and intestinal metaplasia of the stomach in Colombian migrants. $J$ Natl Cancer Inst 1970;44:297-306.

${ }^{8}$ Imai T, Kubo T, Watanabe H. Chronic gastritis in Japanese with reference to high incidence of gastric carcinoma. $J$ Natl Cancer Inst 1971;47:179-95.

${ }^{9}$ Järvi $O$, Laurén $P$. On the role of heterotopias of the intestinal epithelium in the pathogenesis of gastric cancer. Acta Pathol Microbiol Scand 1951;29:26-44.

10 Morson BC. Carcinoma arising from areas of intestinal metaplasia in the gastric mucosa. Br J Cancer 1955; 9:377-85.

${ }^{11}$ Morson BC. Precancerous lesions of upper gastrointestinal tract. JAMA 1962;179:311-5.

${ }^{12}$ Nakamura K, Sugano H, Takagi K, Fuchigami A. Histopathological study on early carcinoma of the 
stomach: some considerations on the ulcer-cancer by analysis of 144 foci of the superficial spreading carcinomas. Gann 1967;58:377-87.

${ }^{13}$ Hirohata T, Kuratsune M. The geographical comparison of mortality from cancer of the stomach and ulcer of the stomach in Japan. Br J Cancer 1969;23:465-79.

${ }^{14}$ Swynnerton BF, Truelove SC. Simple gastric ulcer and carcinoma. Br Med J 1951 ;ii:1243-6.

15 Doll R, Avery Jones F, Pygott F, Stubbe JL. The risk of gastric cancer after medical treatment for gastric ulcer. Gastroenterologia (Basel) 1957;88:1-12.

16 Mosbech J, Videbaek A. Mortality from and risk of gastric carcinoma among patients with pernicious anaemia. Br Med J 1950;ii:390-4.

17 Jørgensen $J$. The mortality among patients with pernicious anemia in Denmark and the incidence of gastric carcinoma among the same. Acta Med Scand 1951;139:472-81.

${ }^{18}$ Shearman DJC, Finlayson NDC, Wilson R, Samson RR. Carcinoma of the stomach and early pernicious anaemia. Lancet 1966 ;ii:403-5.

19 Schell RF, Dockerty MB, Comfort MW. Carcinoma of the stomach associated with pernicious anaemia: clinical and pathologic study. Surg Gynec Obstet 1954;98:710-20.

${ }^{20}$ Zamcheck N, Grable E, Ley A, Norman L. Occurrence of gastric cancer among patients with pernicious anemia at the Boston City Hospital. N Engl J Med 1955;252: 1103-10.

${ }^{21}$ Magnus HA. A re-assessment of the gastric lesion in pernicious anaemia. J Clin Pathol 1958;11:289-95.

${ }^{22}$ Elsborg L, Andersen D, Myhre-Jensen O, Bastrup-Madsen P. Gastric mucosal polyps in pernicious anaemia. Scand J Gastroenterol 1977;12:49-52.

${ }^{23}$ Boyd J, Langman M, Doll R. The epidemiology of gastrointestinal cancer with special reference to causation. Gut 1964;5:196-200.

${ }^{24}$ De Jode LR. Gastric carcinoma following gastro-enterostomy and partial gastrectomy. Br J Surg 1961;48:512-4

${ }^{25}$ Stalsberg H, Taksdal S. Stomach cancer following gastric surgery for benign conditions. Lancet 1971 ;ii:1175-7.

26 Saegesser F, Jämes D. Cancer of the gastric stump after partial gastrectomy (Billroth II principle) for ulcer Cancer 1972;29:1150-9.

27 Nicholls JC. Carcinoma of the stomach following partial gastrectomy for benign gastroduodenal lesions. $\mathrm{Br} J$ Surg $1974 ; 61: 244-9$.

${ }^{28}$ Schrumpf E, Serck-Hanssen A, Stadaas J, Aune S, Myren $\mathrm{J}$, Osnes M. Mucosal changes in the gastric stump 20-25 years after partial gastrectomy. Lancet 1977;ii:467-9.

${ }^{29}$ Ming SC, Goldman H. Gastric polyps: a histogenetic classification and its relation to carcinoma. Cancer 1965;18:721-6.

30 Nakamura T. Pathohistologische Einteilung der Magenpolypen mit spezifischer Betrachtung ihrer malignen Entartung. Chirurg 1970;41:122-30.

31 Elster K. Histologic classification of gastric polyps. Curr Top Pathol 1976;63:77-93.

${ }^{32}$ Murakami T, ed. Early gastric cancer. Gann Monogr Cancer Res 1971;11.

${ }^{33}$ Nagayo T. Histological diagnosis of biopsied gastric mucosa with special reference to that of borderline lesions. Gann Monogr Cancer Res 1971;11:245-56.

${ }^{34}$ Matzner MJ, Raab AP, Spear PW. Benign giant gastric rugae complicated by submucosal gastric carcinoma. Gastroenterology 1951;18:296-302.

${ }^{35}$ Texter EC, Jr, Legerton CW, Jr, Reeves RJ, Smith AG, Ruffin JM. Coexistent carcinoma of the stomach and hypertrophic gastritis. Report of a case with review of the literature. Gastroenterology 1953;24:579-86.

${ }^{36}$ Chusid EL, Hirsch RL, Colcher H. Spectrum of hypertrophic gastropathy. Giant rugal folds, polyposis and carcinoma of the stomach. Case report and review of the literature. Arch Int Med 1964;114:621-8.

${ }^{37}$ Pear EG, Horsch R. Hypertrophic gastritis with malignant deterioration and metastasis to bone. Am J Gastroenterol $1964 ; 42: 280-4$.

${ }^{38}$ Rubin RG, Fink H. Giant hypertrophy of the gastric mucosa associated with carcinoma of the stomach. Am J Gastroenterol 1967;47:379-88.

39 Roux M, Vayre P, Levasseur JC. Gastrite hypertrophique et épithélioma prépylorique. Sem Hop Paris $1968 ; 44$ : 1935-6.

40 Moeller DD, Laing RR, Dunn GD, Klotz AP. Hypertrophic gastropathy and carcinoma of the stomach. Gastroenterology 1969;56:1237. (Abstract)

41 Sarrazin A, Simon J, Bousquet O, Paillas J, Monod-Broca $P$. Un cas de maladie de Ménétrier avec tumeur carcinoide microscopique de l'estomac. Arch Fr Mal App Dig 1971;60:331-6.

42 Hureau J, Delavierre P, Vayre P, Levasseur JC, Bourdais JP, Laburthe-Tolra Y. Association de la gastrite géante hypertrophique avec le cancer d'estomac et avec la polypose gastrique. Sem Hop Paris 1973;49:2042-6.

43 Valencia-Parparcen J, Bruni Celli B. Hypertrophic gastritis versus gastric carcinoma. Am J Gastroenterol 1973;59: 119-33.

${ }^{44}$ Stamatakis JD, Wyatt AP. Ménétrier's disease and carcinoma of stomach. Proc $R$ Soc Med 1976;69:264-5. (Abstract)

45 Dottrens Y. Maladie de Ménétrier et carcinome gastrique. Étude de Quatre Cas. Thèse No. 3611. Geneva: Éditions Médecine et Hygiène, 1977.

46 Grundmann E. Histologic types and possible initial stages in early gastric carcinoma. Beitr Pathol 1975;154:256-80.

47 Oehlert W, Keller P, Henke M, Strauch M. Die Dysplasien der Magenschleimhaut. Dtsch Med Wochenschr 1975; 100:1950-9.

${ }^{48}$ Ming SC. Dysplasia of gastric epithelium. Front Gastrointest Res 1979;4:164-72.

49 Cuello C, Correa P, Zarama G, Lopez J, Murray J, Gordillo G. Histopathology of gastric dysplasias. Correlations with gastric juice chemistry. Am J Surg Pathol 1979;3:491-500.

50 Japanese Research Society for Gastric Cancer. General Rules for Gastric Cancer Study in Surgery and Pathology, 9th ed. Tokyo: Kanehara Shuppan, 1975.

Requests for reprints to: Dr BC Morson, Pathology Department, St Mark's Hospital, City Road, London EC1V 2PS, UK. 